\title{
Delayed Resistance to Plum Pox Potyvirus Mediated by a Mutated RNA Replicase Gene: Involvement of a Gene-Silencing Mechanism
}

\author{
Hui Shan Guo and Juan Antonio García \\ Centro Nacional de Biotecnologia (C.S.I.C.), Campus de la Universidad Autónoma, 28049 Madrid, Spain \\ Received 13 September 1996. Accepted 12 November 1996.
}

\begin{abstract}
Nicotiana benthamiana plants were transformed with intact and mutated nuclear inclusion b (NIb) gene sequences of plum pox potyvirus, Rankovic isolate (PPV-R). The constructs included additional in-frame initiation and termination codons. All of the eight independently transformed lines showed some kind of protection against PPV; however, this protection was largely overcome at high inoculum doses. Interestingly, a phenotype of total recovery from the initial infection was observed in a high percentage of plants of two lines transformed with an NIb coding sequence that carried a Gly to Val mutation at the GDD motif typical of viral RNA replicases. Recovery frequently started with the emergence of dark green patches in the infected leaves that accumulated much less virus than the surrounding tissue. Newly developing leaves were symptomless and virus free, and showed highly effective, and very specific, resistance to virus reinoculation. Both in the dark green patches and in the symptomless leaves, virus decline was accompanied by a drastic reduction in the accumulation of transgene transcripts. Normal transgene mRNA levels and initial susceptibility to infection were recovered in the progeny plants coming from the autofecundation of a recovered plant, indicating that the recovery phenotype is not meiotically stable. The results are discussed in terms of a previously proposed model that links gene silencing and RNA-mediated virus resistance (J. J. English, E. Mueller, and D. C. Baulcombe, Plant Cell 8:179-188, 1996), adapted to explain the recovery phenomenon.
\end{abstract}

Additional keywords: cosuppression, pathogen-derived resistance, replicase-mediated resistance.

In the past few years, different virus-derived genes have been successfully employed to engineer transgenic plants resistant to viral infections in a large number of plant/virus combinations (Fitchen and Beachy 1993; Wilson 1993; Lomonossoff 1995). This form of resistance is known as

Corresponding author: Juan Antonio García; Phone: 34-1-5854535; Fax: 34-1-5854506; E-mail: JGARCIA@ SAMBA.CNB.UAM.ES

This article is in the public domain and not copyrightable. It may be freely reprinted with customary crediting of the source. The American Phytopathological Society, 1997. "pathogen-derived resistance," a concept proposed by Sanford and Johnson in 1985 (Sanford and Johnson 1985). The first genome fragment to be used to generate pathogen-derived resistance, and the one that has been most extensively employed with this aim since then, is the coat protein $(\mathrm{CP})$ gene. The accumulation of the protein itself, rather than the transgene mRNA encoding it, has been shown to be responsible for the resistance, in plants transformed with the $\mathrm{CP}$ gene, to several viruses, such as tobacco mosaic virus (TMV) (Powell et al. 1990), alfalfa mosaic virus (AlMV) (Loesch-Fries et al. 1987), or potato virus X (PVX) (Hemenway et al. 1988). Also, the resistance found in plants transgenic for a defective form of the TMV movement protein seems to be protein-mediated, in this case probably because the mutation has transdominant effects (Lapidot et al. 1993). In all these plants, there was a direct correlation between the level of transgene protein accumulation and the resistance observed.

The transformation of plants with viral RNA replicase sequences has given rise to a much wider range of phenotypes. Frequently, the transgenic plants were highly resistant, but some plants transformed with RNA replicase genes were not only fully susceptible to virus infection but could complement mutant viruses with defects in the corresponding viral gene (Baulcombe 1994; Lomonossoff 1995). In cases of replicasemediated resistance, it has generally proved impossible to detect the presence of protein from the transgene and usually an inverse relationship has been found between the level of expression of the viral transgene and the resistance obtained (Baulcombe 1994; Lomonossoff 1995). On the basis of these data, it has been suggested that all cases of replicase-mediated resistance may be examples of a more general mechanism mediated by RNA that is closely related with the cellular phenomenon known as cosuppression or gene silencing (Baulcombe 1994; Dougherty et al. 1994; English et al. 1996). However, studies of transient expression in protoplasts have suggested that an intact protein is required for RNA replicasemediated resistance against TMV (Carr et al. 1992). Further evidence that RNA replicase itself could be directly involved in the resistance mechanism was provided by Brederode et al. (1995). These authors showed that a mutated AlMV RNA replicase gene, but not the intact one, conferred protection against virus infection to transgenic tobacco plants. On the other hand, a recent report (Tenllado et al. 1995) has indicated that, while some of the transgenic plants transformed with RNA replicase sequences of the pepper mild mottle tobamovi- 
rus (PMMV) were resistant to the virus infection, others showed a phenotype of induced, delayed resistance similar to the recovery phenotype initially described in plants transformed with potyvirus CP genes (Lindbo et al. 1993; Ravelonandro et al. 1993).

The Potyvirus genus is the largest and most widely distributed group of plant viruses (Ward and Shukla 1991). Its genome consists of a (+) sense RNA strand of about $10 \mathrm{~kb}$ that encodes one large polyprotein (Riechmann et al. 1992; Shukla et al. 1994). The putative core protein of the potyvirus RNA replicase is the nuclear inclusion $b(\mathrm{NIb})$ protein, which is synthesized as part of the viral polyprotein, from which it is cleaved off by proteolytic processing. There are few data available on RNA replicase-mediated resistance to potyviruses. Audy et al. (1994) found significant virus resistance in three out of 13 tobacco lines transformed with an engineered NIb gene from potato virus Y (PVY), the type member of the potyvirus group. Although the level of accumulation of the mRNA of the transgene was not assayed and its protein product could not be detected in the transgenic plants, a role for the NIb protein itself in engineering the resistance could be deduced from the fact that 30 transformed tobacco lines expressing essentially the same sequence but deleted for the
Gly-Asp-Asp (GDD) motif were not resistant. In this paper, we describe the transformation of Nicotiana benthamiana plants with the NIb coding sequence of plum pox potyvirus (PPV), intact or mutated at the GDD motif. A variable level of resistance against PPV infection was observed in all the transformed lines. Interestingly, plants expressing an NIb coding sequence in which the GDD motif had been mutated to VDD showed a delayed, very specific, highly resistant phenotype, which was induced by the initial infection.

\section{RESULTS}

\section{Transformation of Nicotiana benthamiana plants with the PPV NIb coding sequence and with its ADD and VDD mutated forms.}

Sequence analysis unambiguously identifies the NIb protein as the viral core of the RNA replicase (Domier et al. 1987), and there are experimental data that demonstrate the involvement of the potyviral NIb protein in RNA replication (Li and Carrington 1995). Individual proteins of PPV are generated by proteolytic processing of the large genomic polyprotein (Fig. 1A); thus, the NIb cistron lacks initiation and termination codons. To express only the PPV NIb coding sequence, a
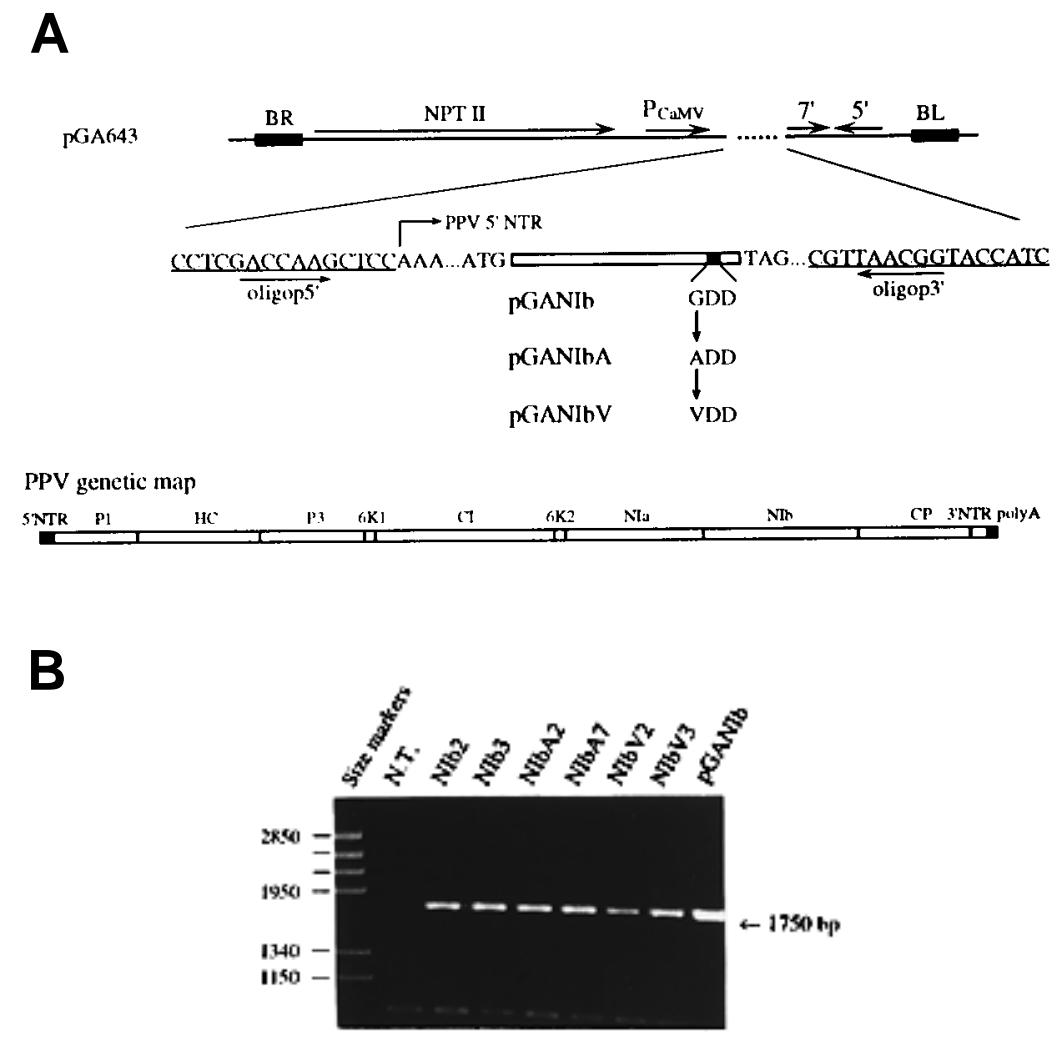

Fig. 1. Detection of plum pox potyvirus (PPV) NIb coding sequence in transgenic plants of the NIb, NIbA, and NIbV series. A, Schematic representation of the series of constructions used for plant transformation. NIb cistron, intact or mutated, and $5^{\prime}$ nontranslated region (NTR) of PPV are inserted in the pGA643 vector, between the $35 \mathrm{~S}$ promoter of cauliflower mosaic virus $\left(\mathrm{P}_{\mathrm{CaMV}}\right)$ and transcription termination signal of genes $7^{\prime}$ and $5^{\prime}$ from plasmid pTiA6. NPTII (neomycin phosphotransferase II) is the selectable marker gene, and BR and BL are right and left, respectively, T-DNA border sequences. Primer sequences used for polymerase chain reaction (PCR) amplification are underlined. Location of NIb coding sequence in PPV genetic map is shown at bottom of the figure. B, Agarose gel analysis of PCR-amplified NIb coding sequence from transgenic plants indicated at top of each lane. PCR amplification products of plasmid pGANIb and of DNA from nontransformed (N.T.) Nicotiana benthamiana plants were used as positive and negative controls, respectively. Numbers on left refer to size (bp) of HindIII restriction fragments of phage Ø29 DNA used as markers. Size of expected amplified fragment is indicated on right of gel. 
Table 1. Infectivity assay of transgenic Nicotinana benthamiana plants of the Nlb, NIbA, and NlbV series challenged with different plum pox potyvirus (PPV) inocula

\begin{tabular}{|c|c|c|c|c|c|c|c|c|c|c|}
\hline \multirow[b]{3}{*}{ Lines } & \multicolumn{6}{|c|}{ Purified virions } & \multirow{2}{*}{\multicolumn{2}{|c|}{$\begin{array}{c}\begin{array}{l}\text { Viral } \\
\text { RNA }\end{array} \\
\mathbf{3 . 5}^{\mathbf{c}}\end{array}$}} & \multirow{2}{*}{\multicolumn{2}{|c|}{$\begin{array}{c}\text { Crude } \\
\text { extract }^{\mathrm{d}}\end{array}$}} \\
\hline & \multicolumn{2}{|c|}{$0.5^{\mathrm{c}}$} & \multicolumn{2}{|c|}{$5^{\mathrm{c}}$} & \multicolumn{2}{|c|}{$100^{c}$} & & & & \\
\hline & $\mathbf{N}^{\mathbf{a}}$ & $\mathbf{R}^{\mathbf{b}}$ & $\mathbf{N}$ & $\mathbf{R}$ & $\mathbf{N}$ & $\mathbf{R}$ & $\mathbf{N}$ & $\mathbf{R}$ & $\mathbf{N}$ & $\mathbf{R}$ \\
\hline $\begin{array}{l}\text { N.T. } \\
\text { pGA643 }\end{array}$ & $\begin{array}{l}0 / 6 \\
0 / 6\end{array}$ & & $\begin{array}{l}0 / 10 \\
0 / 10\end{array}$ & & $\begin{array}{l}0 / 4 \\
0 / 4\end{array}$ & & $\begin{array}{l}0 / 3 \\
0 / 3\end{array}$ & & $\begin{array}{c}0 / 6 \\
0 / 10\end{array}$ & \\
\hline $\begin{array}{l}\text { Nlb2 } \\
\text { NIb3 }\end{array}$ & $\begin{array}{l}10 / 13 \\
8 / 10\end{array}$ & $\begin{array}{l}2 / 13 \\
1 / 10\end{array}$ & $\begin{array}{c}0 / 6 \\
1 / 14\end{array}$ & & $\begin{array}{l}\mathrm{ND}^{\mathrm{f}} \\
0 / 6\end{array}$ & & $\begin{array}{l}\text { ND } \\
2 / 5\end{array}$ & & $\begin{array}{l}1 / 5 \\
0 / 6\end{array}$ & $2 / 6$ \\
\hline $\begin{array}{l}\text { NIbA2 } \\
\text { NIbA3 } \\
\text { NIbA4 } \\
\text { NIbA7 }\end{array}$ & $\begin{array}{c}11 / 13 \\
11 / 13 \\
8 / 14 \\
11 / 16\end{array}$ & $\begin{array}{l}2 / 13 \\
6 / 14 \\
2 / 16\end{array}$ & $\begin{array}{c}1 / 14 \\
0 / 14 \\
0 / 8 \\
0 / 3\end{array}$ & & $\begin{array}{l}\text { ND } \\
0 / 6 \\
\text { ND } \\
0 / 6\end{array}$ & & $\begin{array}{l}\mathrm{ND} \\
\mathrm{ND} \\
\mathrm{ND} \\
2 / 3\end{array}$ & & $\begin{array}{l}\text { ND } \\
0 / 6 \\
\text { ND } \\
\text { ND }\end{array}$ & \\
\hline $\begin{array}{l}\text { NlbV2 } \\
\text { NIbV3 }\end{array}$ & $\begin{array}{c}5 / 8 \\
6 / 13\end{array}$ & $\begin{array}{c}2 / 8 \\
4 / 13\end{array}$ & $\begin{array}{l}1 / 16 \\
3 / 14\end{array}$ & $\begin{array}{l}6 / 16 \\
4 / 14\end{array}$ & $\begin{array}{l}\text { ND } \\
\text { ND }\end{array}$ & & $\begin{array}{l}4 / 8 \\
4 / 7\end{array}$ & $\begin{array}{l}3 / 8 \\
2 / 7\end{array}$ & $\begin{array}{c}0 / 6 \\
2 / 26\end{array}$ & $\begin{array}{c}5 / 6 \\
23 / 26\end{array}$ \\
\hline
\end{tabular}

${ }^{\mathrm{a}}$ Reaction: number of noninfected plants as a function of the total number of inoculated plants.

${ }^{b}$ Reaction: number of plants that show phenotypes of partial or total recovery as a function of the total number of inoculated plants.

${ }^{c}$ Concentration $(\mu \mathrm{g} / \mathrm{ml})$.

${ }^{d}$ Two milliliters of extraction buffer per $1 \mathrm{~g}$ of leaf tissue. This extract produced 70 lesions per leaf in Chenopodium foetidum (virus titre $>100 \mu \mathrm{g} / \mathrm{ml})$.

${ }^{\text {e }}$ Nontransformed.

${ }^{\mathrm{f}}$ Nondetermined.
DNA fragment encompassing its full-length sequence flanked by ATG and TAG codons was synthesized by polymerase chain reaction (PCR). This fragment was cloned downstream of the sequence encoding the PPV $5^{\prime}$ nontranslated region (NTR) in a pUC19 derivative, giving rise to pUGNIb. Undesirable mutations introduced during PCR amplification were discarded by replacing most of the PPV sequence cloned in pUGNIb with the corresponding one of an infectious cDNA clone, and sequencing the remaining NIb sequence.

The translatability of the PPV construction of pUGNIb was verified by translation in a reticulocyte lysate system of in vitro synthesized RNA, after subcloning in the plasmid pGEM3 (data not shown).

The tripeptide Gly-Asp-Asp forms part of a very conserved motif (GDD motif) typical of the RNA replicases. It has been reported that substitutions of Val or Ala for Gly in the GDD domain of the $\mathrm{Q} \beta$ phage RNA replicase engender nonfunctional proteins that interfere with the activity of the wild-type enzyme (Inokuchi and Hirasima 1987). Gly to Ala and Gly to Val mutations were introduced in the PPV NIb coding sequence of pUGNIb by site-directed mutagenesis originating pUGNIbA and pUGNIbV, respectively.

$N$. benthamiana plants were transformed by the disarmed Agrobacterium tumefaciens strain LBA 4404 harboring pGANIb, pGANIbA, or pGANIbV, all three of which contained the $5^{\prime}$ NTR-NIb constructions of the plasmids of the pUGNIb series cloned in the shuttle vector pGA643. Eight

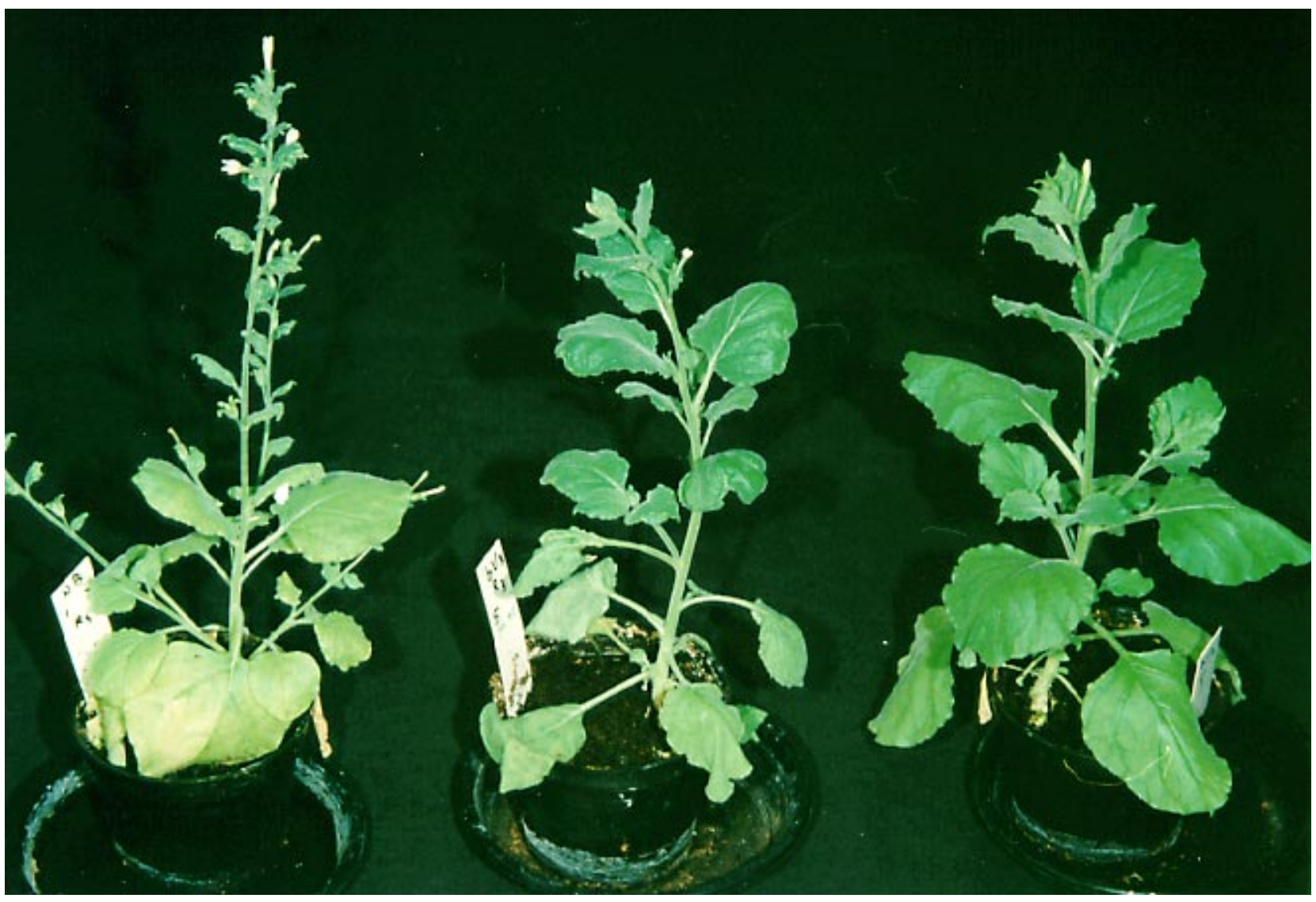

Fig. 2. Plant of the NIbV3 line recovered from plum pox potyvirus infection, flanked by infected (left) and healthy (right) Nicotiana benthamiana plants. 
transgenic plants transformed with the PPV constructions (lines NIb2 and 3, NIbA2, 3, 4, and 7, and NIbV2 and 3) and one plant transformed with the vector (control line pGA643) were regenerated in the presence of kanamycin. Transgenic plants were normal in appearance and grew and developed like nontransgenic plants.

The presence of the entire NIb coding sequence in all the transgenic plants was determined by PCR amplification of its genomic DNA with primers specific to the ends of the $\mathrm{NIb}$ gene (data not shown). These data were confirmed in two lines of each construction by PCR amplification with primers that hybridize with the vector regions flanking the cloning site of the NIb coding sequence in the pGA643 plasmid (Fig $1 B)$. DNA sequencing of the corresponding PCR products corroborates the presence of the Gly to Ala and Gly to Val mutations in the transgenes of the NIbA and NIbV lines, respectively.

\section{Susceptibility of NIb transgenic plants to virus infection.}

Self-fertilized kanamycin-resistant $\mathrm{R}_{1}$ progeny plants of the independently transformed lines were inoculated with $0.5 \mu \mathrm{g}$ of purified PPV-R per ml (Table 1). This concentration of inoculum is enough to infect $100 \%$ of nontransformed $N$. benthamiana plants. Typically, PPV-R causes a striking chlorosis and curling in the systemically infected leaves of $N$. benthamiana that appears at 5 to 7 days post inoculation (dpi), followed by growth inhibition of newly developing leaves. Control plants transformed with the vector pGA643 showed the same susceptibility to infection and the same kind of symptoms as the nontransformed plants. All the lines transformed with the NIb coding sequence, both intact and mutated, showed some kind of protection against PPV infection, reflected in a lower percentage of infected plants, attenuation and delay in the appearance of symptoms, and/or reduction in virus accumulation. It is interesting that by $15 \mathrm{dpi}$ symptoms in young leaves from some infected plants start to decline, with a parallel reduction in the levels of virus accumulation estimated by enzyme-linked immunosorbent assay (ELISA). This recovery was only partial in plants of the NIb2 and 3, and NIbA3, 4, and 7 lines, but newly developing leaves of some plants of the NIbV2 and 3 lines did not show any kind of visible symptoms (Fig. 2) and remained permanently virus-free according to ELISA data (not shown). A symptom completely different from those associated with normal PPV disease was observed in some NIbV plants (Fig. 3), preceding establishment of the complete recovery phenotype. Well-defined patches of dark green tissue emerged on the chlorotic, infected leaves; this tissue seemed to grow more actively than surrounding tissue, and eventually acquired a bubble-like appearance. ELISA (Fig. 3) and back inoculation experiments (not shown) indicated that virus accumulation in the dark green areas was considerably reduced, compared with the rest of the infected leaf.

The percentage of plants from any of the transgenic lines that resulted infected drastically rose at higher doses of inoculum (Table 1). Only some delay in symptom development was observed in some cases. However, many of the NIbV2 and NIbV3 plants showed the recovery phenotype, even when they were inoculated with undiluted sap from infected plants (virus titre higher than $100 \mu \mathrm{g} / \mathrm{ml}$ according to ELISA data and local lesions produced in Chenopodium foetidum).

\section{Expression of the NIb coding sequence}

in the transgenic plants.

The products of transcription of the NIb gene of two transgenic lines from each construction were analyzed by Northern (RNA) blot analysis (Fig. 4). In all the samples of plants transformed with the PPV NIb coding sequence, a major band was detected, with an electrophoretic mobility corresponding to about $1.7 \mathrm{~kb}$, that was consistent with a transcript composed of the PPV $5^{\prime}$ NTR, the NIb coding sequence, the bordering vector sequences, and a poly(A) tail. There was some variation in the intensity of the bands from the different samples; however, these differences seem to be not significant since they were not reproduced in other experiments and are also found in samples from the same line. The hybridization band was absent in samples of either nontransformed plants or plants transformed with the nonrecombinant vector alone that were used as control. The integrity of the transgene mRNAs was verified by reverse transcription (RT)-PCR amplification of total RNA extracted from the transgenic plants, with primers specific to vector sequences that flank the NIb gene and that should be transcribed (Fig. 4B). A DNA fragment of the expected size was produced that was not amplified from RNA of the control plants or when the reverse transcriptase was omitted in the first step of the reaction. Restriction enzyme analysis confirmed the identity of the amplified product.
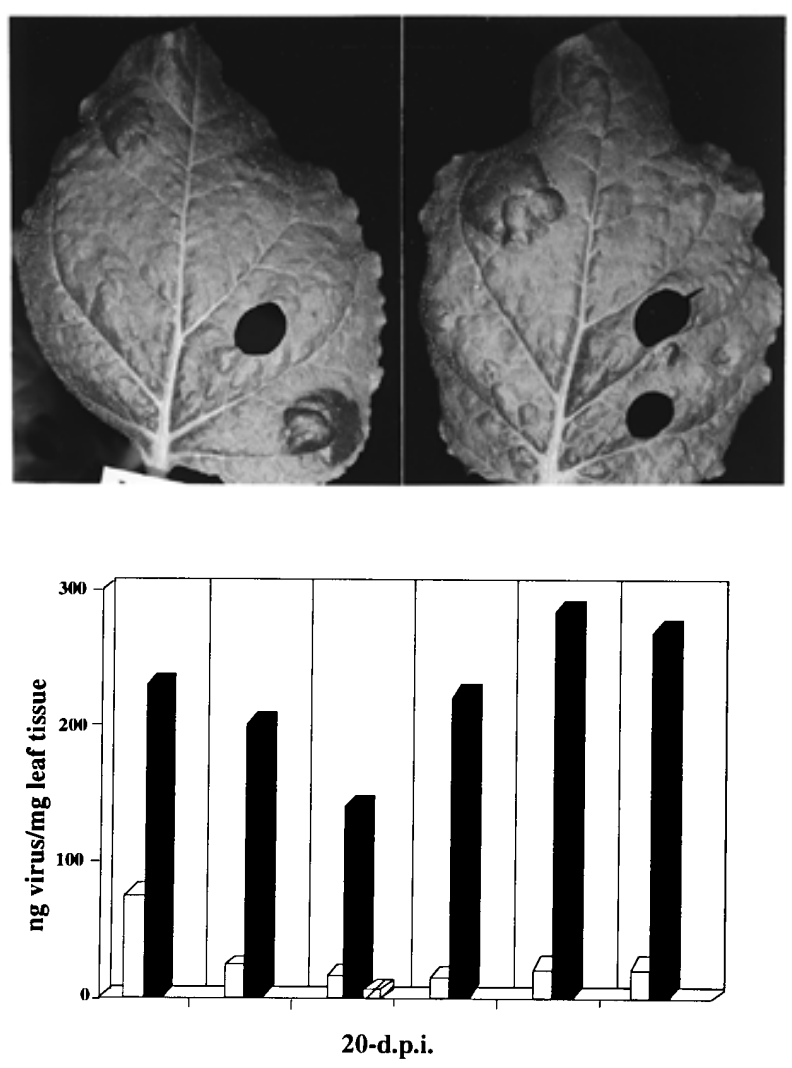

Fig. 3. Leaves of NIbV3 plants that are being recovered and show typical dark green patches ("bubbles"). Amount of virus, estimated by enzyme-linked immunosorbent assay, present in dark green patches from different plants (open bars) and in surrounding tissue (solid bars) is shown in lower panel. Viral accumulation in apical tissue of one plant is also shown (striped bar). 
We were unable to detect the protein product of the $\mathrm{NIb}$ transgene by Western blot (immunoblot) analysis with an antiserum that permitted detection of the NIb protein in extracts of PPV-infected plants diluted 100 times (data not shown). At present, we do not know whether the transgene protein accumulates at low levels because it is not efficiently synthesized or because it is unstable when synthesized outside the context of the viral infection.
Resistance to reinfection of recovered transgenic plants.

The results described above clearly indicate that the plants from the transgenic lines NIbV2 and NIbV3 are able to show the phenotype of complete recovery independently of the doses of inoculum applied. The back inoculation experiment depicted in Figure 5A shows that, although the young, asymptomatic leaves of the recovered plants were virus free, the old leaves continued to have the virus after they had re-
A.
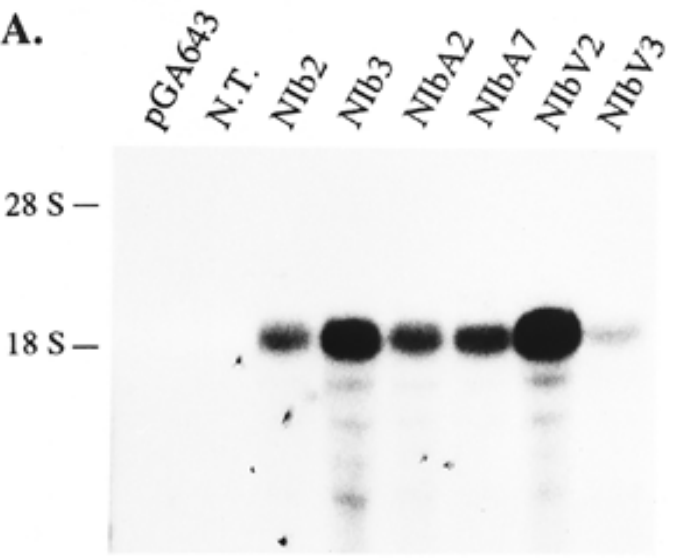

B.
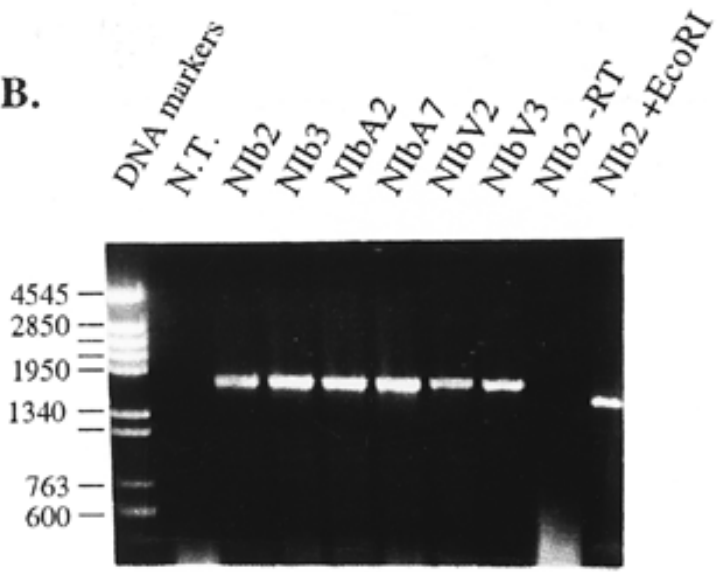

Fig. 4. Detection of transgene mRNA in transgenic plants of the NIb, NIbA, and NIbV series. A, Northern (RNA) blot analysis of total RNA (10 $\mu \mathrm{g}$ ) purified from transgenic plants indicated at top of each lane. Samples from nontransformed (N.T.) or vector-transformed (pGA643) plants were used as negative controls. The position of ribosomal RNAs $28 \mathrm{~S}$ and $18 \mathrm{~S}$ was determined by methylene blue staining of membrane. B, Agarose gel analysis of products of reverse transcription-polymerase chain reaction (RT-PCR) amplifications, using as templates $1 \mu \mathrm{g}$ of total RNA purified from transgenic plants indicated at top of each lane. -RT indicates that reverse transcriptase was omitted in the first step of the reaction; +EcoRI indicates that the RTPCR product was digested with EcoRI. Numbers on left refer to size (bp) of HindIII restriction fragments of phage Ø29 DNA used as markers.

A

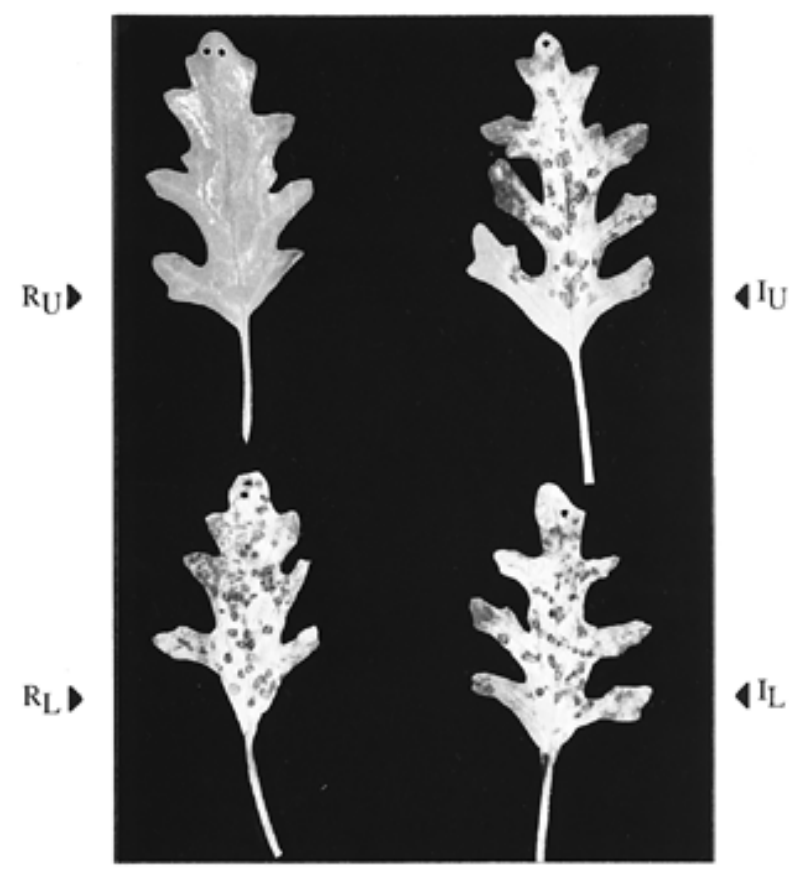

B

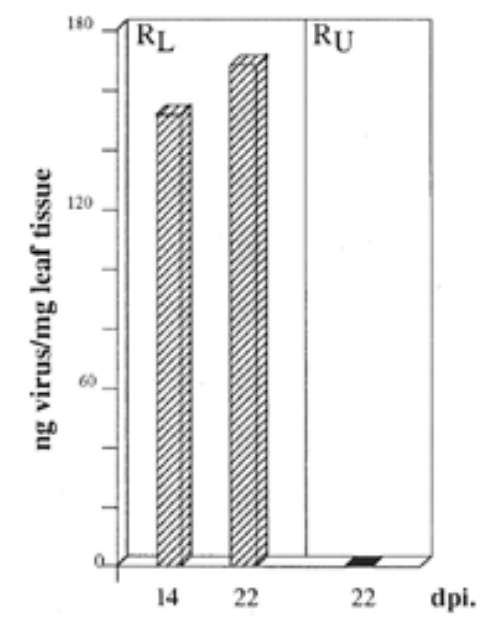

Fig. 5. Analysis of virus distribution in recovered plants. A, Back inoculation on Chenopodium foetidum with extracts from newly developing ( $\mathrm{R}_{\mathrm{U}}$ and $\left.I_{U}\right)$ and old $\left(R_{L}\right.$ and $\left.I_{L}\right)$ leaves from a recovered $\left(R_{U}\right.$ and $\left.R_{L}\right)$ and a nonrecovered $\left(I_{U}\right.$ and $\left.I_{L}\right)$ plant. B, Plum pox potyvirus accumulation, estimated by enzyme-linked immunosorbent assay (ELISA), in a single infected leaf $\left(\mathrm{R}_{\mathrm{L}}\right)$, before (14 days post inoculation [dpi]) and after (22 dpi) plant recovery, and in a newly developing leaf $\left(\mathrm{R}_{\mathrm{U}}, 22 \mathrm{dpi}\right)$ of same plant. Detection limit of ELISA measures in this experiment: ca. $5 \mathrm{ng}$ of virus per mg of leaf tissue. 
covered. ELISA data indicate that virus accumulation in these leaves did not decline when the recovery status was being established in the plant (Fig. 5B). This result calls into question whether the universally accepted term "recovery" is the most appropriate to designated this kind of phenotype, since leaves initially infected do not recover from the infection and newly developing leaves are free of virus from the beginning.

In order to determine whether newly developing leaves are virus free as the result of a blockage of the virus movement or because of the induction of authentic resistance, they were challenged with different sources of inoculum (Fig. 6). When these leaves were treated at 28 dpi with high doses of purified PPV-R $(100 \mu \mathrm{g} / \mathrm{ml})$, neither disease symptoms nor virus multiplication could be detected in newly developing leaves. On the contrary, the recovered plants were fully susceptible to another potyvirus, tobacco vein mottling virus (TVMV), when inoculated with purified virions at a concentration of $1 \mu \mathrm{g} / \mathrm{ml}$. The level of similarity between TVMV and PPV-R at the NIb region is about $65 \%$. In a second experiment, the recovered plants were challenged with PPV-R and with a second strain of PPV, PPV-PS, using crude extracts of infected leaves as a source of inoculum. As control, leaves of a similar developing stage of NIbV3 plants that had not been previously inoculated were challenged with the same inocula. Whereas the control plants were infected independently of the strain of PPV used as inoculum, the NIbV3-recovered plants were susceptible to PPV-PS but not to PPV-R. Taking into account that the level of similarity between PPV-R and PPV-PS in the region of the transgene is $84 \%$, these results indicate that the recovery of the NIbV transgenic plants results in a very specific resistance condition.

\section{Relationship between transgene mRNA levels and recovery.}

In order to ascertain if the competence of a transgenic plant to recover after PPV infection is related to the levels of the transgene transcripts, leaf samples of NIb3, NIbV2, and NIbV3 plants were collected before they were inoculated with PPV-R. Northern blot analysis showed that the levels of $\mathrm{NIb}$ mRNA before the inoculation were similar in NIb3-1 and NIbV2-1 plants (Fig. 7A, lanes 2 and 3) that did not recover from the infection, and in NIbV2-5, NIbV3-5, and NIbV3-1 plants (Fig. 7A, lanes 4 to 6), that developed the recovery phenotype. Interestingly, the amount of transgene mRNA dropped to almost undetectable levels in the young, asymptomatic leaves of the recovered plants (Fig. 7A, lanes 7 and 8).

Another recovery experiment is shown in Figure 7B. A strong band of NIb mRNA was detected in a 5- $\mu \mathrm{g}$ sample of

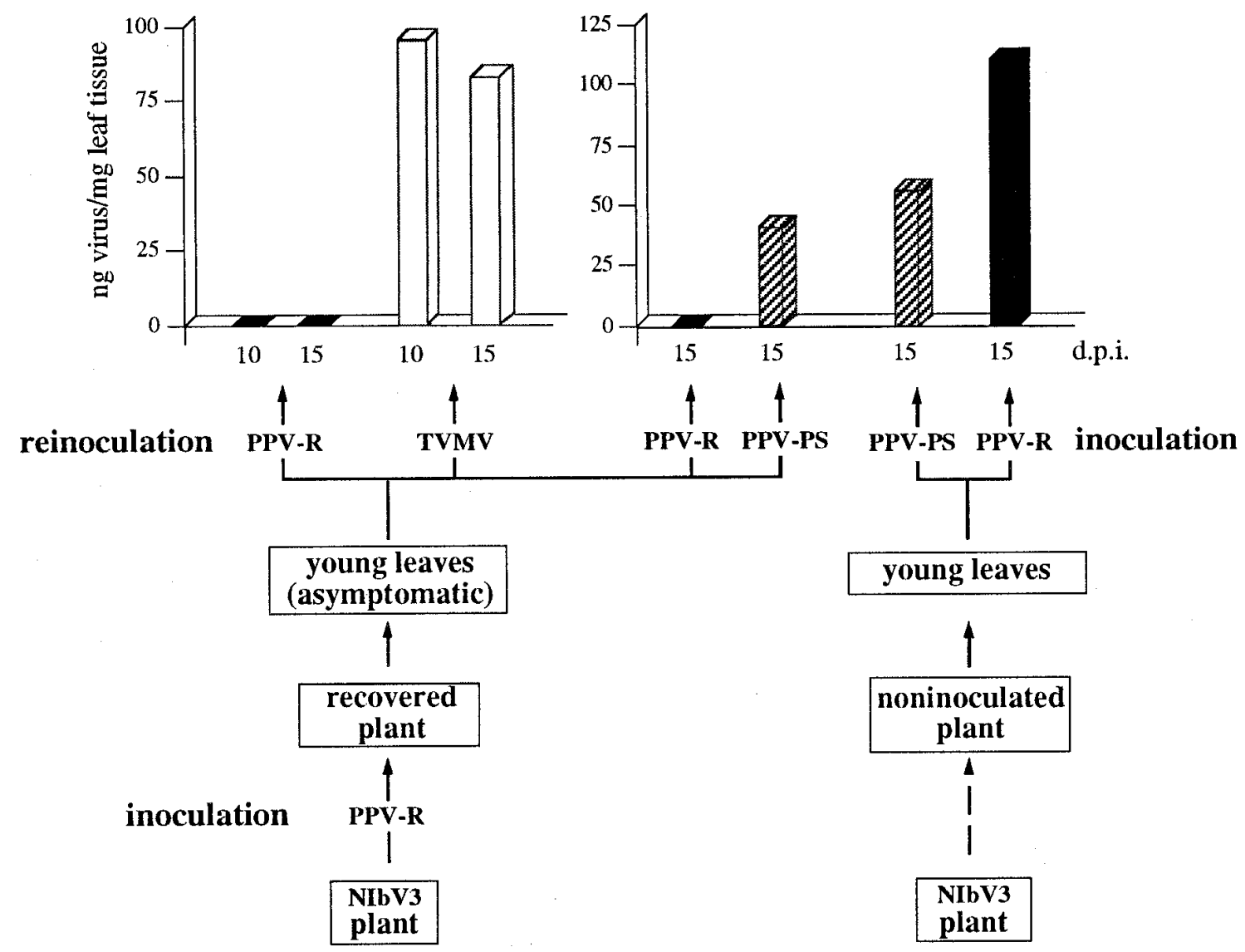

Fig. 6. Analysis of susceptibility to reinfection of recovered tissue. Asymptomatic young leaves of recovered NIbV3 plants were inoculated with plum pox potyvirus isolates PPV-R and PPV-PS, and tobacco vein mottling virus. As controls, leaves of NIbV3 plants not previously infected, the same age as those inoculated in recovered plants, were challenged with PPV-R and PPV-PS. On the days after the second inoculation that are indicated in the picture, viral accumulation was determined by enzyme-linked immunosorbent assay (ELISA) in samples collected from leaves above the inoculated ones. Detection limit of ELISA measures in this experiment: ca. $5 \mathrm{ng}$ of virus per mg of leaf tissue. 
total RNA extracted from a leaf of the NIbV3-4 plant collected before inoculation (lane 2). However, NIb mRNA was practically undetectable when $20 \mu \mathrm{g}$ of RNA extracted from young leaves of the same plant after the recovery were analyzed (lane 4). A similar reduction in the levels of accumulation of transgene mRNA was noticeable in the dark green patches of the infected leaves of the NIbV3-4 plant (lane 7). It was not possible to assess the transgene mRNA levels in the infected tissue of nonrecovered plants or in the tissue that surrounds the dark green areas, because of the excessive hybridization background derived from the large accumulation of PPV RNA as a consequence of multiplication of the virus (not shown).

The decrease in transgene transcript levels was not an effect of the developmental stage of the plant, since the amount of NIb mRNA detected in a noninoculated NIbV3 plant of the same age as the recovered plants (Fig. 7B, lanes 8 and 9) was similar to that present in the leaves collected before the inoculation.

From the results described above it was not possible to discriminate whether the decline in the levels of transgene mRNA in the recovered plants was related to the recovery mechanism or to the viral infection. To gain insight into this question, we analyzed the transgene NIb mRNA levels in NIbV3 transgenic plants before and after they were infected with TVMV. No recovery was apparent after systemic infection of NIbV3 plants with TVMV. The presence of the PPV $\mathrm{NIb}$ transgene mRNA could be analyzed in the TVMVinfected plants thanks to the fact that the RNA coming from the multiplication of this virus was not recognized by the PPV-specific probe used in the Northern blot experiment (Fig. 8 , lane 7). It was very clear that, in contrast to the drastic decrease in NIb mRNA levels after infection and recovery of PPV-inoculated plants (Fig. 8, lanes 1 and 2), the amount of transgene transcript was not reduced in TVMV-infected plants, which do not show the recovery phenomenon (Fig. 8, lanes 3 to 6).

\section{Susceptibility to the infection and levels of transgene mRNA accumulation in the progeny of recovered NIbV3 plants.}

Seeds were collected from the NIbV3-5 plant that had been self-fertilized after it had recovered from the initial PPV infection. Twenty plants germinated from these seeds in the presence of kanamycin were inoculated with crude sap from PPV-infected plants. The susceptibility of the progeny of the recovered plant to the infection seemed to be similar to that of the parental NIbV3 plants. Nineteen of the 20 inoculated NIbV3-5 progeny plants became infected, indicating that the resistance condition of the recovered NIbV3-5 plant had not been transmitted to its progeny. All the infected plants showed the typical recovery phenotype.

Although the NIb mRNA of the NIbV3-5 plant was practically undetectable after recovery (before self-fertilization) (Fig. 9, lanes 2 and 3), the levels of transgene mRNA were high in the progeny of this plant (Fig. 9, lanes 4 and 6). These levels dropped again in the young, asymptomatic leaves after the recovery (Fig. 9, lanes 5 and 7), corroborating the paral-
A.
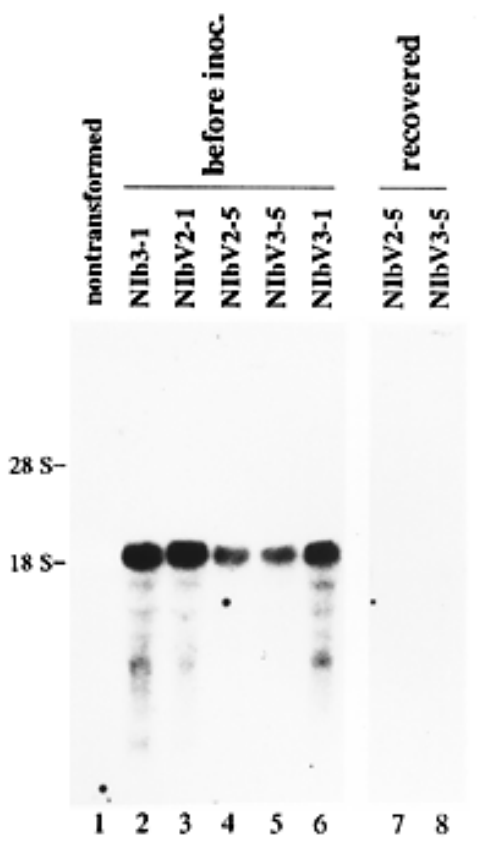

B.
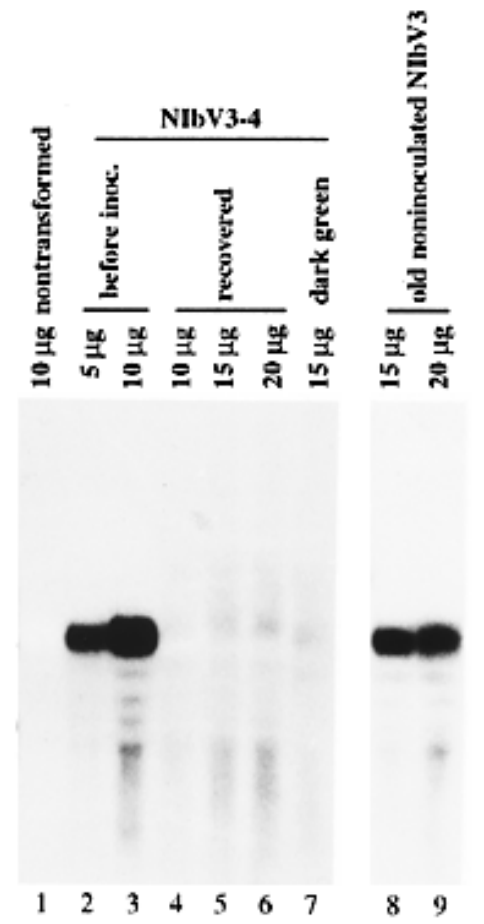

Fig. 7. Northern (RNA) blot analysis of transgene RNA accumulation in plants of the NIb3, NIbV2, and NIbV3 lines indicated at top of lanes. Total RNA was extracted from young leaves before plants were inoculated (A, lanes 2 to 6; B, lanes 2 and 3) and, after recovery, from newly developing (asymptomatic) leaves (A, lanes 7 and 8; B, lanes 4 to 6), and from dark green patches of infected leaves (B, lane 7). B, The samples of lanes 8 and 9 correspond to leaves of noninoculated plants in same developmental stage as leaves of recovered plants analyzed in the experiment. As a negative control, RNA from nontransformed plants was also analyzed (A and $\mathbf{B}$, lane 1). When not indicated at top of the lane, amount of RNA loaded on gel was 10 $\mu \mathrm{g}$. Position of ribosomal RNAs $28 \mathrm{~S}$ and $18 \mathrm{~S}$, determined by methylene blue staining, is shown to left of $\mathbf{A}$. 
lelism between the resistance condition and the low levels of accumulation of the transgene mRNA.

\section{DISCUSSION}

In the last few years a number of cases of resistance to viruses of several genera mediated by the RNA replicase gene have been described (Carr and Zaitlin 1993; Baulcombe 1994). There are clear indications that, at least in some of these cases, the resistance was mediated by activation of a host mechanism that specifically degrades viral RNA, similar to that proposed to give protection in plants transformed with potyviral CP genes (Dougherty et al. 1994). This degradation mechanism seems to be closely related to the cosuppression phenomenon, in which the presence of a transgene leads to the suppression of expression ("silencing") of both the transgene and its homologous endogenous counterpart (Chasan 1994; Mueller et al. 1995). However, there are also examples of resistance mediated by RNA replicase genes that seem not to be caused by gene silencing (Brederode et al. 1995, Tenllado et al. 1995). In some of these cases, it has been postulated that the RNA replicase protein itself is involved in the resistance mechanism (Carr et al. 1992, Brederode et al. 1995).

No data are available on the levels of the protein and mRNA transgene products that were present in susceptible and resistant transgenic plants transformed with the RNA replicase (NIb) gene of PVY, the potyvirus type member (Audy et al. 1994). However, the fact that a small deletion in a region that encodes part of the active center of the enzyme had a drastic effect on the ability of the transgene to confer protection also points to participation of the protein product of the transgene in this first case of replicase-mediated resistance against a potyvirus.

We did not observe an extreme resistance phenotype in plants transformed with the wild-type NIb coding sequence of

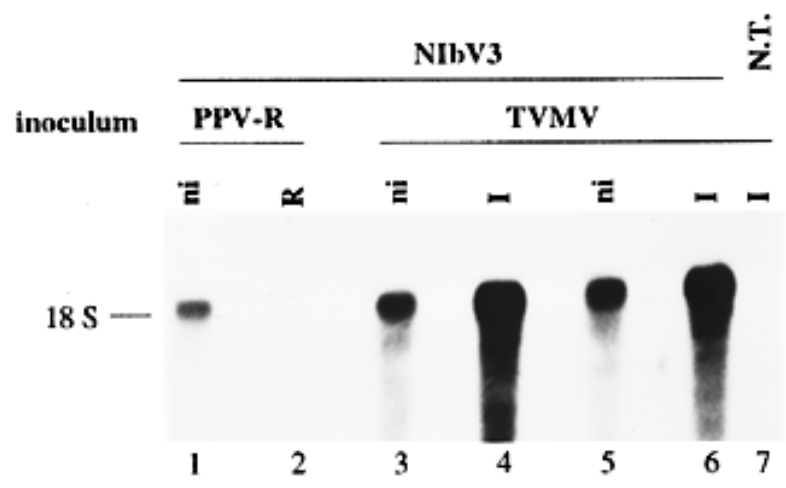

Fig. 8. Effect of virus infection on transgene mRNA accumulation. Total RNA was extracted from young leaves of individual NIbV3 plants before they were inoculated (ni, lanes 1, 3, and 5), from asymptomatic leaves of a plant recovered from plum pox potyvirus (PPV) infection ( $R$, lane 2), and from equivalent leaves of nonrecovered plants infected with tobacco vein mottling virus (TVMV) (I, lanes 4, 6). As a control, total RNA was also extracted from a nontransformed (N.T.) plant inoculated with TVMV (I, lane 7). Samples of adjacent lanes (1 and 2, 3 and 4, and 5 and 6) came from same plant. Five micrograms (lanes 1, 3, 5, and 7) or $10 \mu \mathrm{g}$ (lanes 2, 4, and 6) of the RNA samples were subjected to Northern (RNA) blot analysis with a PPV NIb-specific probe. Position of ribosomal RNA $18 \mathrm{~S}$, determined by methylene blue staining, is shown beside panel.
PPV. This is probably because of the low number of transgenic lines analyzed, since only a small proportion of the lines transformed with the PVY NIb coding sequence described by Audy et al. (1994) were highly resistant to virus infection. Similarly, only weak resistance to initial infection, which was easily overcome when high concentration inocula were used, could be detected in the lines transformed with GDD-mutated versions of the PPV NIb coding sequence. However, later on, a very specific resistance condition was established in newly developing leaves of a high proportion of plants of the NIbV2 and NIbV3 lines, transformed with a mutated PPV NIb that has a Val substituting to Gly in the GDD motif. This phenotype has not been described previously for plants transformed with a potyvirus NIb coding sequence, but resembles the recovery phenomenon that was first observed in plants transformed with sense and antisense forms of potyvirus CP genes (Lindbo et al. 1993; Ravelonandro et al. 1993; Cassidy and Nelson 1995; Hammond and Kamo 1995) and that has recently been shown to also be induced by a genomic fragment encompassing the $6 \mathrm{kDa} / 21 \mathrm{kDa}$ reading frames of tobacco etch potyvirus (Swaney et al. 1995) and by the 54-kDa region of the PMMV replicase gene (Tenllado et al. 1995).

Is the delayed resistance of the NIbV2 and NIbV3 transgenic lines mediated by the transgene mRNA or by the protein translated from it? The close correlation between resistance and low levels of transgene mRNA accumulation that we have found in the NIbV2 and NIbV3 lines strongly suggests that the protection is mainly mediated by RNA through an "induced" cosuppression mechanism. However, as in the plants transformed with the RNA replicase genes of AlMV and PVY (Brederode et al. 1995; Audy et al. 1994), the presence of mutations at the GDD motif of the PPV NIb coding sequence seems to affect the induction of resistance. Although we have not analyzed a large enough number of NIb transgenic lines to draw definitive conclusions, taken as a whole the results of the

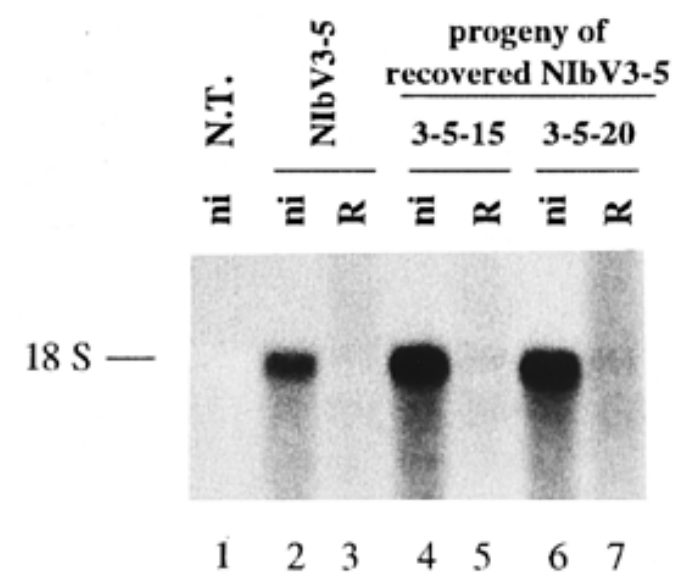

Fig. 9. Northern (RNA) blot analysis of transgene mRNA accumulation in a recovered NIbV3 plant (NIbV3-5, lanes 2,3) and in two progeny plants (NIbV3-5-15 and NIb3-5-20, lanes 4 to 7) obtained by autofecundation of the recovered NIbV3-5 plant. Samples of total RNA extracted before inoculation ( $5 \mu \mathrm{g}$, ni, lanes 2,4 , and 6$)$ and after recovery of the plum pox potyvirus (PPV) infection (10 $\mu \mathrm{g}, \mathrm{R}$, lanes 3,5 , and 7) were loaded on the gel. As a negative control, RNA from healthy nontransformed (N.T.) plants (10 $\mu \mathrm{g}$, lane 7) was also analyzed. Position of ribosomal RNA 18S, determined by methylene blue staining, is shown beside panel. 
analysis of the three viruses suggest that the RNA replicase protein itself might play some role in the induction of virus resistance that would require the presence of the GDD region and that would be enhanced by point mutations in this domain. On the other hand, the possibility that the minor mutations at the GDD sequence might alter the ability to mediate resistance of the mRNA encoded by the replicase transgene should not be ruled out.

The cosuppression phenomenon has been explained as a response to excessive synthesis of a particular mRNA (Lindbo et al. 1993; Meyer 1995). In this model, the recovery phenotype would appear when transgene mRNA accumulation before inoculation is too low to switch on the degradation mechanism (susceptibility to the infection), but the additive level of the transgene transcript and the genomic RNA derived from the viral multiplication exceeds the threshold level and activates the system (recovery and resistance) (Smith et al. 1995). However, taking into account that the level of viral multiplication is much higher than the level of expression of the transgene, it is difficult to explain merely on the basis of the threshold model why the RNA derived from the viral replication is able to cooperate with the transgene mRNA to reach the activation level, but does not surpass the threshold by itself, giving rise to recovery even in the infections of nontransgenic plants. Thus, it is necessary to invoke the existence of the "unknown genome feature" postulated by Mueller et al. (1995) to justify why a transgene does or does not cause resistance depending on the insertion loci. It has been postulated that this unknown factor could be related to the methylation status of the transgene and might be involved in the synthesis of aberrant transcripts (aRNA), which would be the primary agent responsible for the activation of the specific degradation system in the cytoplasm (English et al. 1996). Interestingly, English et al. (1996) proposed that the same products of the gene-silencing mechanism could reinforce the "unknown genome feature," closing a feedback cycle. This model was designed to explain the resistance mediated by the PVX replicase gene, which does not result in the recovery phenotype. We propose a refinement of the model that would allow, on the basis of its postulates, interpretation of the recovery phenotype. According to our assumptions, the action of an inefficient genome feature could be strengthened by viral infection, giving rise to activation of the gene-silencing mechanism. The feedback would give rise to enough reinforcement to maintain the resistance even when the viral infection that switched on the process has ceased.

Other peculiarities of the recovery phenotype that we have observed in the NIbV2 and NIbV3 lines can also be explained on the basis of this model. Assuming that the feedback cycle can be transmitted through mitosis, the virus-free, recovered cells would multiply more actively than the neighboring, infected ones. As consequence, recovered tissue emerging in an infected leaf would grow more rapidly than the surrounding tissue, and would acquire the typical bubble appearance. When recovery took place in meristemic tissue, all the shoots derived from it would be virus free and protected against further inoculations with the same virus. The phenotype of "partial recovery" could be the result of a genome feature too inefficient to maintain the gene-silencing cycle active only by feedback, and, as a consequence, the resistance status would be lost when the level of virus multiplication fell below a specific level.
According to the model of English et al. (1996), the aRNA would serve as a template for a plant-encoded, RNAdependent RNA polymerase ( $\mathrm{RdRp}$ ). The resultant antisense RNA (asRNA) molecules would drive the target RNA to the degradation mechanism. An interesting guess is that activation of the gene-silencing mechanism during recovery is the consequence of a more efficient synthesis of asRNA because of the increase of the RdRp levels that has been shown to occur in some viral infections (Dorssers et al. 1983). However, our data indicate that the TVMV infection does not provoke recovery. Hence, activation of this process cannot be controlled exclusively by the RdRp levels, which would be similarly affected by the PPV and TVMV infections, and it would be necessary to introduce in the hypothesis an additional factor that conferred specificity to the process.

As mentioned above, English et al. (1996) proposed that the transgene activation that causes the synthesis of aRNA, and as a consequence gene silencing, is related to the methylation state of part of its sequence, and that resetting DNA methylation at meiosis could break the cycle of cosuppression induction. In perfect agreement with this hypothesis, plants of the progeny of the recovered NIbV3-5 plant are susceptible to PPV infection (with subsequent recovery) and have high levels of transgene mRNA similar to those of the parental plant before it was inoculated.

A prediction that can be deduced from the present model is that, when the genome feature of the transgene has an intermediate degree of efficiency, not only virus infection but also other factors can activate the cycle that gives rise to gene silencing and, as a consequence, to viral resistance. In agreement with this prediction, it has been reported that factors dependent on plant development and environmental conditions determine the post-transcriptional transgene silencing and consequent resistance to tomato spotted wilt in transgenic lettuce, especially when the transgene dosage is low (Pang et al. 1996).

Although the model of English et al. (1996), revised with the new elements postulated in this paper, seems to harmonize all data reported on virus resistance mediated by gene silencing, most of the key elements of the model remain to be identified and further research is required to unravel the mechanisms of action of pathogen-derived resistance.

\section{MATERIALS AND METHODS}

Virus isolates.

The PPV Rankovic (PPV-R) and PPV-PS isolates were obtained from D. Z. Maat (Instituut voor Plantenziektenkundig Onderzoek, Wageningen, The Netherlands) and M. Rankovic (Fruit Research Institute, Čačak, Serbia), respectively, and were propagated in Nicotiana clevelandii. Virus and virion RNA were purified as described previously (Laín et al. 1988). The TVMV used in the experiments reported in this paper was a gift from E. Rodríguez-Cerezo.

\section{Construction of transgenes.}

The PPV NIb coding sequence was amplified by PCR with the PPV-R full-length cDNA clone pGPPV as template (Riechmann et al. 1990), linearized with PvuII. The upstream primer used for the amplification was 5'-TCCAAAACTACA CATTGGCTCAGAGATAG-3', which corresponds to nucleo- 
tides (nt) 7023 to 7051 of the PPV-R genome sequence (Laín et al. 1989). The downstream primer was 3'-GTTGCAACAA CACGTGGTTATCCTAGGGC-5' ${ }^{\prime}$ complementary to nt 8558 to 8576 of the PPV-R RNA sequence. This oligodeoxynucleotide was designed to create a TAG stop codon (bold face) behind the NIb coding sequence and to insert a BamHI site (underlined). After digestion with T4 DNA polymerase and BamHI, the amplified product was ligated into a fragment of plasmid pUGP1 (to be described elsewhere) that contained the PPV $5^{\prime}$ NTR and an ATG initiation codon in the context of an NcoI restriction site. This pUGP1 fragment was obtained by treatment with $N c o$ I, filling in with Klenow and further digestion with BamHI. In order to correct possible mistakes caused by the low fidelity of the Taq DNA polymerase used for the PCR amplification, the EcoRI-ClaI fragment (PPV nt 7171 to 8309) of the resulting plasmid was replaced by the corresponding fragment of pGPPV, giving rise to plasmid pUGNIb. The accuracy of the ligation borders and of the not-exchanged NIb sequences was verified by DNA sequencing.

Point mutations at the GDD motif of the PPV NIb coding sequence were produced by site-directed mutagenesis of a BamHI-EcoRV fragment (PPV nt 6930 to 8514) subcloned into an M13 vector, employing the method described by Kunkel et al. (1987) and 5'-GTGAATG(C/T)TGATGATC-3' as mutagenic oligodeoxynucleotide mixture. Replacement of the BglII-ClaI (PPV nt 7236 to 8310) of pUGNIb by the corresponding ones containing the Gly to Val and Gly to Ala mutations yielded the plasmids pUGNIbV and pUGNIbA, respectively.

The plasmids pGANIb, pGANIbV, and pGANIbA were obtained by inserting the KpnI-XbaI fragments of pUGNIb, pUGNIbV, and pUGNIbA, which contain the PPV $5^{\prime}$ NTR and NIb sequences, into the HindIII and XbaI sites of the expression cassette of the binary vector pGA643 (An et al. 1988). To make the KpnI and HindIII ends compatible, the restriction fragments were treated with Klenow before the $X b a I$ digestion. The pGA643 derivatives were transferred into the non-oncogenic A. tumefaciens strain LBA-4404 by electroporation.

\section{Plant transformation.}

$N$. benthamiana plants were transformed by Agrobacteriummediated leaf disk transformation (Horsch et al. 1985). Transgenic plants were regenerated on a selection medium containing kanamycin $(100 \mu \mathrm{g} / \mathrm{ml})$. Rooted plantlets were transferred to soil and, after an adaptation period in a climate room at a humidity of $70 \%$, they were maintained in a greenhouse.

Neomycin phosphotransferase (NPT) activity was assayed on leaf extracts of the regenerated plants following the method described by McDonnell et al. (1987). The presence of the NIb coding sequence was determined by PCR analysis of genomic DNA isolated from leaf tissue and purified by $\mathrm{CsCl}$ gradient centrifugation (Sambrook et al. 1989). Amplification was carried out with the oligodeoxynucleotides 5'-CCTCG ACCAAGCTCC-3' (oligo p5') and 3'-GCAATTGCCATGGT AG-5') (oligo p3') used as primers, homologous to pGA643 sequences that flank the HindIII and $\mathrm{XbaI}$ sites used to clone the NIb coding sequence. PCR amplification was performed with Taq polymerase (USB, Cleveland, $\mathrm{OH}$ ) and $0.5 \mu \mathrm{g}$ of plant genomic DNA.

\section{Analysis of RNA.}

Total RNA was isolated from leaf tissue by the $\mathrm{LiCl}$ precipitation method described by Verwoerd et al. (1989). For RT-PCR analysis, first cDNA synthesis from $1 \mu \mathrm{g}$ of total RNA, previously treated with RNase-free DNase, was carried out with AMV reverse transcriptase (Seikagaku, Ijamsville, $\mathrm{MD}$ ), with oligo p3' used as primer. The reaction product was amplified by PCR as indicated in the above paragraph.

For Northern analysis, total RNA was separated on a $1.2 \%$ agarose gel containing $6 \%$ formaldehyde, and transferred to a Zeta-probe membrane (Bio-Rad, Hercules, CA) (Sambrook et al. 1989). The blot was hybridized with a ${ }^{32} \mathrm{P}$-labeled riboprobe specific to the PPV NIb coding sequence, synthesized by in vitro transcription with the MAXIscript kit (Ambion, Austin, TX).

\section{Virus resistance experiments.}

Self-pollinated progeny plants, germinated in the presence of kanamycin, were inoculated approximately 3 weeks after being transferred to soil. Ten microliters of purified virus, viral RNA, or a 1:2 dilution (wt/vol) of virus-infected tissue homogenate, was applied to a leaf dusted lightly with Carborundum. When an extract from infected leaves was used as inoculum, its virus titre was estimated by immunoreaction in Western blots and ELISA, and by counting the number of local lesions produced in $C$. foetidum. The same conditions were used for the inoculation of asymptomatic upper leaves when transgenic plants were challenged after recovery from the initial infection.

Visual evaluation of symptoms and virus determination by indirect ELISA were routinely used to assess virus infection. In some instances, either Northern blot or RT-PCR analysis was used to search for accumulation of viral RNA, and, when it was convenient, the production of infectious virus was estimated by back inoculation on the local lesion host $C$. foetidum.

\section{ACKNOWLEDGMENTS}

We wish to thank Elvira Domínguez for her excellent technical assistance. This work was supported by grants BIO95-0076 from CICYT and AE00423/95 from the Comunidad de Madrid. Hui Shan Guo received fellowships from the Instituto de Cooperación al Desarrollo and DGICYT.

\section{LITERATURE CITED}

An, G., Ebert, P. R., Mitra, A., and Ha, S. B. 1988. Binary vectors. Pages A5:1-9 in: Plant Molecular Biology Manual. S. B. Gelvin, R. A. Schilperoort, and D. P. S. Verma, eds. Kluwer Academic, Dordrecht, The Netherlands.

Audy, P., Palukaitis, P., Slack, S. A., and Zaitlin, M. 1994. Replicasemediated resistance to potato virus $\mathrm{Y}$ in transgenic tobacco plants. Mol. Plant-Microbe Interact. 7:15-22.

Baulcombe, D. C. 1994. Replicase-mediated resistance: A novel type of virus resistance in transgenic plants? Trends Microbiol. 2:60-63.

Brederode, F. T., Taschner, P. E. M., Posthumus, E., and Bol, J. F. 1995. Replicase-mediated resistance to alfalfa mosaic virus. Virology 207: 467-474.

Carr, J. P., Marsh, L. E., Lomonossoff, G. P., Sekiya, M. E., and Zaitlin, M. 1992. Resistance to tobacco mosaic virus induced by the 54-kDa gene sequence requires expression of the 54-kDa protein. Mol. PlantMicrobe Interact. 5:397-404.

Carr, J. P., and Zaitlin, M. 1993. Replicase-mediated resistance. Semin. Virol. 4:339-347. 
Cassidy, B. G., and Nelson, R. S. 1995. Differences in protection phenotypes in tobacco plants expressing coat protein genes from peanut stripe potyvirus with or without an engineered ATG. Mol. PlantMicrobe Interact. 8:357-365.

Chasan, R. 1994. Making sense (suppression) of viral RNA-mediated resistance. Plant Cell 6:1329-1331.

Domier, L. L., Shaw, J. G., and Rhoads, R. E. 1987. Potyviral proteins share amino acid sequence homology with picorna-, como-, and caulimoviral proteins. Virology 158:20-27.

Dorssers, L., van der Meer, J., van Kammen, A., and Zabel, P. 1983. The cowpea mosaic virus RNA replication complex and the host-encoded RNA-dependent RNA polymerase-template complex are functionally different. Virology 125:155-174.

Dougherty, W. G., Lindbo, J. A., Smith, H. A., Parks, T. D., Swaney, S. and Proebsting, W. M. 1994. RNA-mediated virus resistance in transgenic plants: Exploitation of a cellular pathway possibly involved in RNA degradation. Mol. Plant-Microbe Interact. 7:544-552.

English, J. J., Mueller, E., and Baulcombe, D. C. 1996. Suppression of virus accumulation in transgenic plants exhibiting silencing of nuclear genes. Plant Cell 8:179-188.

Fitchen, J. H., and Beachy, R. N. 1993. Genetically engineered protection against viruses in transgenic plants. Annu. Rev. Microbiol. 47: 739-763.

Hammond, J., and Kamo, K. K. 1995. Effective resistance to potyvirus infection conferred by expression of antisense RNA in transgenic plants. Mol. Plant-Microbe Interact. 8:674-682.

Hemenway, C., Fang, R.-X., Kaniewski, W., Chua, N.-H., and Turner, N. E. 1988. Analysis of the mechanism of protection in transgenic plants expressing the potato virus $\mathrm{X}$ coat protein or its antisense RNA. EMBO J. 7:1273-1280.

Horsch, R. B., Fry, J., Hoffmann, N. L., Wallroth, M., Eichholtz, D. Rogers, S. G., and Fraley, R. T. 1985. A simple and general method for transferring genes into plants. Science 227:1229-1231.

Inokuchi, Y., and Hirasima, A. 1987. Interference with viral infection by defective RNA replicase. J. Virol. 61:3946-3949.

Kunkel, T. A., Roberts, J. D., and Zakour, R. A. 1987. Rapid and efficient site-specific mutagenesis without phenotypic selection. Pages 367-382 in: Methods in Enzymology. R. Wu and L. Grossman, eds. Academic Press, San Diego, CA.

Laín, S., Riechmann, J. L., and García, J. A. 1989. The complete nucleotide sequence of plum pox potyvirus RNA. Virus Res. 13:157172.

Laín, S., Riechmann, J. L., Méndez, E., and García, J. A. 1988. Nucleotide sequence of the $3^{\prime}$ terminal region of plum pox potyvirus RNA. Virus Res. 10:325-342.

Lapidot, M., Gafny, R., Ding, B., Wolf, S., Lucas, W. J., and Beachy, R. N. 1993. A dysfunctional movement protein of tobacco mosaic virus that partially modifies the plasmodesmata and limits virus spread in transgenic plants. Plant J. 4:959-970.

Li, X. H., and Carrington, J. C. 1995. Complementation of tobacco etch potyvirus mutants by active RNA polymerase expressed in transgenic cells. Proc. Natl. Acad. Sci. USA 92:457-461.

Lindbo, J. A., Silva-Rosales, L., Proebsting, W. M., and Dougherty, W. G. 1993. Induction of a highly specific antiviral state in transgenic plants: Implications for regulation of gene expression and virus resistance. Plant Cell 5:1749-1759.

Loesch-Fries, L. S., Merlo, D., Zinnen, T., Burhop, L., Hill, K., Krahn, K., Jarvis, N., Nelson, S., and Halk, E. 1987. Protection against tobacco mosaic virus infection in transgenic plants requires accumula- tion of coat protein rather than coat protein RNA sequences. EMBO J. 6:1845-1851.

Lomonossoff, G. P. 1995. Pathogen-derived resistance to plant viruses. Annu. Rev. Phytopathol. 33:323-343.

McDonnell, R. E., Clark, R. D., Smith, W. A., and Hinchee, M. A. 1987. A simplified method for the detection of nemycin phosphotransferase II activity in transformed plant tissues. Plant Mol. Biol. Rep. 5:380386

Meyer, P. 1995. Understanding and controlling transgene expression. Trends Biotechnol. 13:332-337.

Mueller, E., Gilbert, J., Davenport, G., Brigneti, G., and Baulcombe, D. C. 1995. Homology-dependent resistance: Transgenic virus resistance in plants related to homology-dependent gene silencing. Plant J. 7:1001-1013.

Pang, S. Z., Jan, F.-J., Carney, K., Stout, J., Tricoli, D. M., Quemada, H. D., and Gonsalves, D. 1996. Post-transcriptional transgene silencing and consequent tospovirus resistance in transgenic lettuce are affected by transgene dosage and plant development. Plant J. 9:899-909.

Powell, P. A., Sanders, P. R., Tumer, N., Fraley, R. T., and Beachy, R. N. 1990. Protection against tobacco mosaic virus infection in transgenic plants requires accumulation of coat protein rather than coat protein RNA sequences. Virology 175:124-130.

Ravelonandro, M., Monsion, M., Delbos, R., and Dunez, J. 1993. Variable resistance to plum pox virus and potato virus $\mathrm{Y}$ infection in transgenic plants expressing plum pox virus coat protein. Plant Sci. 91:157-169.

Riechmann, J. L., Laín, S., and García, J. A. 1990. Infectious in vitro transcripts from a plum pox potyvirus cDNA clone. Virology 177: 710-716.

Riechmann, J. L., Laín, S., and García, J. A. 1992. Highlights and prospects of potyvirus molecular biology. J. Gen. Virol. 73:1-16.

Sambrook, J., Fritsch, E. F., and Maniatis, T. A. 1989. Molecular Cloning: A Laboratory Manual. 2nd ed. Cold Spring Harbor Laboratory, Cold Spring Harbor, NY.

Sanford, J. C., and Johnson, S. A. 1985. The concept of parasite-derived resistance: deriving resistance genes from the parasites own genome. J. Theor. Biol. 115:395-405.

Shukla, D. D., Ward, C. W., and Brunt, A. A. 1994. Genome structure, variation and function. Pages 74-112 in: The Potyviridae. D. D Shukla, C. W. Ward, and A. A. Brunt, eds. CAB Int., Cambridge, UK.

Smith, H. A., Powers, H., Swaney, S., Brown, C., and Dougherty, W. G. 1995. Transgenic potato virus Y resistance in potato: Evidence for an RNA-mediated cellular response. Phytopathology 85:864-870.

Swaney, S., Powers, H., Goodwin, J., Silva Rosales, L., and Dougherty, W. G. 1995. RNA-mediated resistance with nonstructural genes from the tobacco etch virus genome. Mol. Plant-Microbe Interact. 8:10041011 .

Tenllado, F., García-Luque, I., Serra, M. T., and Dáz-Ruiz, J. R. 1995. Nicotiana benthamiana plants transformed with the 54-kDa region of the pepper mild mottle tobamovirus replicase gene exhibit two types of resistance responses against viral infection. Virology 211:170-183.

Verwoerd, T. C., Dekker, B. M. M., and Hoekema, A. 1989. A small scale procedure for the rapid isolation of plant RNAs. Nucleic Acids Res. 17:2362.

Ward, C. W., and Shukla, D. D. 1991. Taxonomy of potyviruses: Current problems and some solutions. Intervirology 32:269-296.

Wilson, T. M. A. 1993. Strategies to protect crop plants against viruses: Pathogen-derived resistance blossoms. Proc. Natl. Acad. Sci. USA 90: 3134-3141. 